\title{
perifèria
}

Número 4, junio 2006

www.periferia.name

\section{Observaciones y primeras conclusiones de una etnografía en el ámbito del poder en un pueblo del Malí}

\author{
Bruno Beny Le Noir - UAB
}

\begin{abstract}
The recent decentralization process in the political organization of Mali fostered the emergence of new political actors that cannot be controlled by the traditional authority of villages. Those new leaders control the new local organizations and are brokers between the state and the locality through the new rhetoric of "decentralization" and "development" and pursue their own profit despite the community needs.
\end{abstract}

\section{Resumen}

La reciente descentralización efectiva de la organización política de Malí ha permitido el desarrollo de nuevos líderes locales opuestos a los líderes tradicionales. Estos líderes utilizan las organizaciones locales como fuente de influencia y ejercen un rol de intermediación con el estado, ayudados por la retórica de la "descentralización" y el "desarrollo", a pesar que persiguen sus propios intereses a menudo contrarios a las necesidades de las comunidades locales.

En la región del África Occidental, el país del Malí ha llevado a cabo un proceso profundo de descentralización con el objetivo declarado de hacer que los propios actores locales (entiéndase las fuerzas civiles locales, asociaciones varias, ONGs, municipalidades...) gestionen sus propios recursos y sean los protagonistas de su propio desarrollo. La reforma en sí ha supuesto la división administrativa del país en 703 municipios -que equivaldrían a otras tantas comarcas en nuestro país, y que por lo tanto están compuestos de varios pueblos- con sus respectivos centros de poder. Hasta 1998, año de la verdadera puesta en marcha de la descentralización y de las primeras elecciones municipales, no existía la figura del alcalde. Es decir, que decisiones financieras y de otra naturaleza van a ser por lo tanto tomadas por los propios interesados a través de sus representantes en el seno de órganos electos. Ahora bien, se requiere que estos dirigentes posean las debidas capacidades técnicas y administrativas, que dispongan realmente de los medios financieros y materiales necesarios para satisfacer las grandes expectativas de la población... Condiciones que no existen en un país que por un lado es

\footnotetext{
${ }^{1}$ Correo Electrónico: bruno_beny@hotmail.com
} 


\section{perifèria}

Número 4, junio 2006

www.periferia.name

considerado como uno de los más pobres del mundo y que por lo tanto cuenta con escasos recursos y con pocos medios y vías de comunicación, con una gran proporción de población rural todavía bastante aislada; y que por otro lado está pasando de un sistema de gobierno muy centralizado a una descentralización exhaustiva en un breve lapso de tiempo. Se prevé que esta reforma no estará rodada hasta pasados unos cuantos años.

En esta zona como en el resto de los países del África Occidental, los pueblos están gobernados por un jefe y un consejo de notables. Asimismo existen una serie de jefes locales -pues también reciben el nombre de jefes- que gestionan los recursos naturales, hay por lo tanto un jefe de las tierras, que reparte las tierras cultivables entre la población de una zona, un jefe del agua, que decide y reparte las zonas de pesca, un jefe de los pastos, que hace lo mismo con las tierras para el ganado. Todas estas funciones no se solapan entre ellas puesto que cada uno de estos actores cumple una serie de prerrogativas y de funciones preestablecidas que marca la tradición y se reproducen en el seno de un grupo de parentesco. Cabría pensar que los jefes del pueblo, portadores del tradicional sistema político local, se pondrían por inercia o por capacidad (suelen estar al centro de las redes influyentes) al frente de los municipios. Pero no es así, ya que la etnografía nos demuestra que ahora no son las mismas personas las que además de acaparar el poder en sus pueblos respectivos también lo acaparan a nivel municipal.

En definitiva, la consecuencia inmediata de la reforma, a nivel local y rural, ha sido que de alguna manera se ha modificado la estructura sociopolítica tradicional poniendo en entredicho el poder del jefe. En el ámbito del poder, en la elección de las personalidades que lo ostenten, una propuesta de cambio, la descentralización, venida del exterior, se enfrenta a dinámicas locales de legitimaciones consuetudinarias. Lo cual da lugar a nuevos espacios de poder, y a la aparición de otros líderes "diferentes" de los tradicionales notables del pueblo.

Hablo en función de la observación experimentada durante el trabajo de campo que he realizado en el pueblo de Saba, en el centro-norte del Malí, más concretamente en la región del Delta Central del río Níger, de agosto a diciembre del 2003. Espacio de tiempo ciertamente insuficiente para poder estar seguro de mis conclusiones, que por lo demás exigen para confirmarse de observaciones repetidas rehaciendo la misma experiencia. Pero todo tiene un principio y sólo pretendo aquí presentar 


\section{perifèria}

Número 4, junio 2006

www.periferia.name

un aspecto de mi experiencia etnográfica. Invito a todas las personas que deseen más puntualizaciones a ojear la tesina "Poder y jefatura locales frente a descentralización nacional en el pueblo de Saba, Malí-municipio de Dialloubé, región de Mopti, Malí-".

En primer lugar voy a presentar algunas impresiones sobre el trabajo de campo que he llevado a cabo, y en segundo lugar paso a explicar un tema de mi investigación.

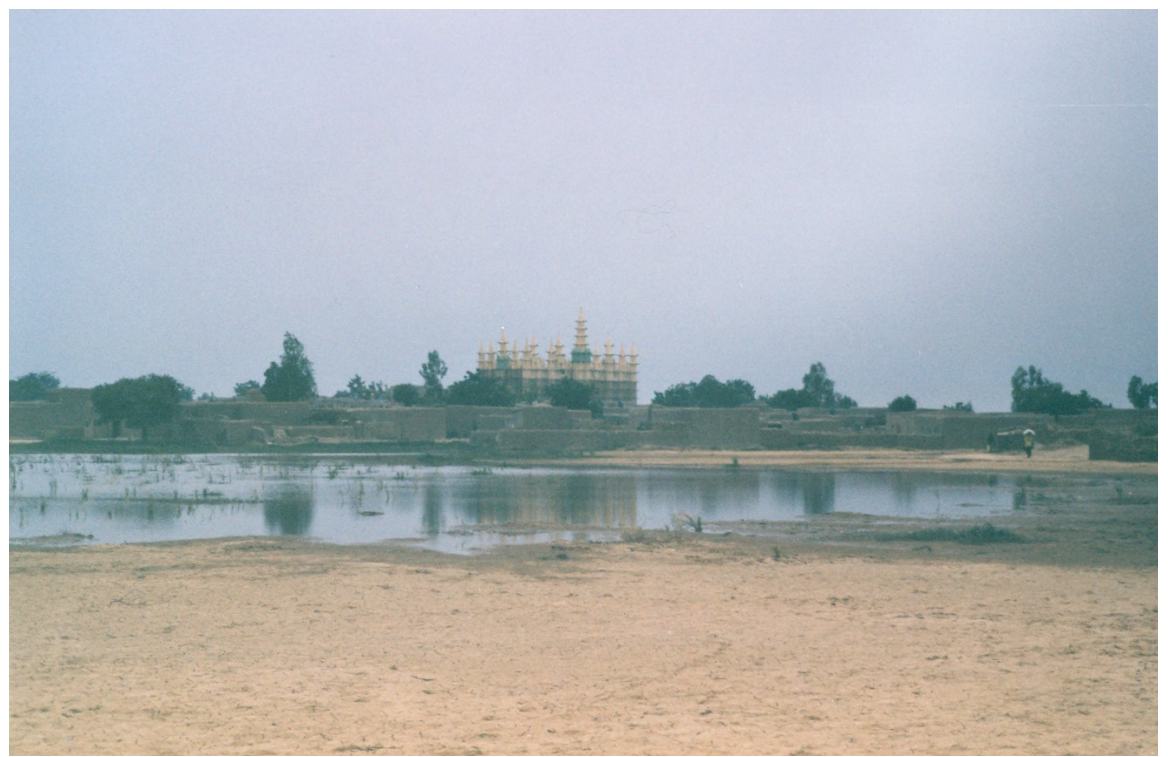

Ilustración 1. Vista de Saba.

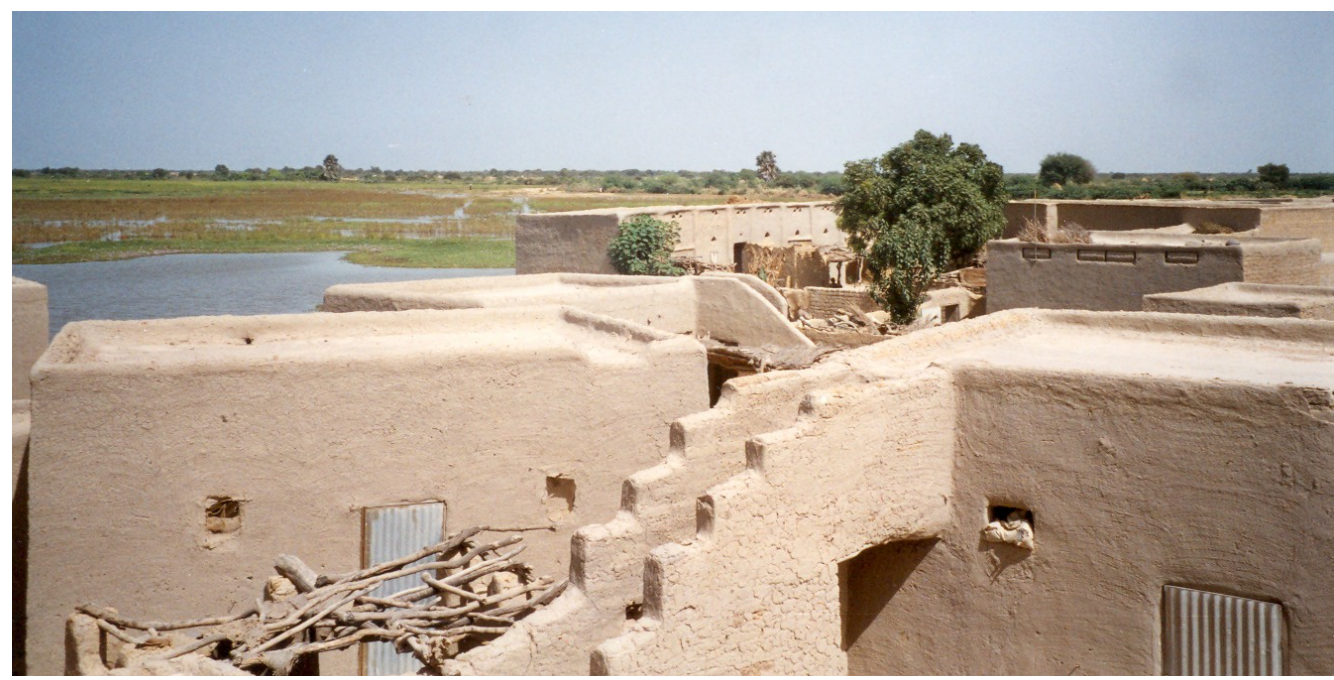

Ilustración 2. Otra vista del pueblo, desde la azotea de una casa. A lo lejos, arrozales. 


\section{perifèria}

Número 4, junio 2006

www.periferia.name

\section{Experiencia personal de trabajo de campo}

La observación participante (recogida en el diario de campo), sobre todo, y las entrevistas semiestructuradas, fueron las técnicas de investigación más utilizadas. En las primeras entrevistas solía recibir respuestas cortas, y a veces evasivas, envueltas en silencios embarazosos. Muy pronto me di cuenta de que estaba "quemando la información". Pensaba que sería difícil volver a tratar los mismos temas: efectivamente contestar mejor a una pregunta siempre equivale a confesar que la primera vez no se había dicho todo lo que se sabía. Al final todo resultó ser una elucubración. Las mejores entrevistas siempre tuvieron lugar de noche, en un ambiente de naturalidad y confianza, a veces acompañados de más gente que poco a poco se iban, dejando su lugar a otros con quienes tenía más confianza el entrevistado. Éste se sentía más libre para decir ciertas cosas o hacerme a su vez preguntas.

De esta forma resultó que muy a menudo, sin yo tener que pedirlo, el propio entrevistado volvía a retomar el hilo que había abandonado al principio de la entrevista o el tema que había quedado inacabado o impreciso, y lo completaba. Por lo tanto las entrevistas solían acabar con los mismos temas con los que habían empezado. Lo principal, como siempre, era no forzar nada. O bien iba a ver a otras personas que me permitían precisar las preguntas futuras que quería hacer a tal o tal persona de la que quería obtener cierta información. Creo que fue la mejor forma de romper barreras, porque suele ocurrir muy a menudo que los entrevistados se ciñen en exceso a la pregunta y no empiezan a "tejer" por sí mismos. Sin hablar de lo corriente que era, sobre todo al principio, que no entendieran las preguntas, ioh dichosos códigos sociales y culturales! En definitiva las entrevistas de mayor calidad sólo llegaron cuando yo aprendí a hacer las preguntas. En las primeras semanas no aprendí gran cosa en cuanto a investigación; pero sí a situarme y a moverme por el pueblo y entre sus gentes. Conociendo y haciéndome conocer, poco a poco empezó a ser natural verme caminar por el pueblo, y nadie se extrañaba ya de ver a un blanco residiendo en Saba. Las entrevistas de calidad llegaron cuando empecé a ser un "bien mueble" del pueblo: "Bourema Quo" (Bourema el de tez clara); cuando empecé a tener "amigos" y personas con las que más hablaba; cuando aprendí a saludar en 


\section{perifèria}

Número 4, junio 2006

www.periferia.name

djenaama y a decir cuatro frases. Fue entonces que encontré mis puntos de referencia y mis paseos favoritos y que empezó verdaderamente mi investigación

La principal dificultad a la que me enfrenté fue la lengua. No hay nada como hablar la lengua local. Valga decir que hablar o hacerse hablar a través de un intérprete implica un filtro de entrada y otro de salida sin contar los otros dos que hay del lado del interlocutor. He preferido muchas veces ir a hablar sólo con personas que hablaban poquísimo francés para poder así asegurarme de la información. Lo que me valió la incomprensión del intérprete a cambio de gozar de mucha más complicidad con los informantes. Pues ésta es la máxima frustración que siempre se da con el intérprete: sin su presencia no puede haber comunicación, pero con su presencia la interacción directa con los habitantes es difícil; y además produce la muy desagradable sensación de no estar nunca solo, de sentirse controlado o censurado.

También hay que citar como dificultad, aunque siempre la tuve presente, el peligro del exotismo (en los dos sentidos). Los universos vírgenes ya no existen -sobre todo a nivel de representaciones. Un investigador, sea blanco o negro, así como un miembro del Gobierno o alguien que pueda ser juzgado como tal, penetra en un mundo de representaciones, construido y lógico, en el que los autóctonos ya lo han clasificado, incluso antes mismo de su llegada. Los sentimientos de las personas hacia él no serán sólo el fruto del periodo que permanecerá con ellos sino también de la historia pasada y actual entre los habitantes y el grupo del que piensan que el visitante procede. Todo ello hace una bonita frase pero sólo es a posteriori que uno se da cuenta de la inercia que producen las representaciones. En el momento todo parece normal y fruto de las relaciones personales que uno mismo va tejiendo con los habitantes.

El trabajo de campo -parte fundamental del trabajo etnográfico-, suele ser lento y a veces monótono... pero sobre todo intermitente. La observación de prácticas que resultan ser interesantes para el antropólogo, y la realización de entrevistas, son hechos que son fundamentales pero no siempre enriquecedores. Me explico: la realidad del etnólogo en el terreno consiste primero en una serie de actos improductivos a primera vista para el estudio propiamente dicho, llámesele la rutina, la banalidad de la vida cotidiana, los días que pasan. Al cabo de poco tiempo uno se da cuenta que de "observador", nada; como máximo, "observado consciente 


\section{perifèria}

Número 4, junio 2006

www.periferia.name

de serlo". El tiempo no transcurre en balde sino que nos sumerge en un mundo de relaciones: de hecho transcurre sobre todo en espacios sociales, espacios domésticos, células familiares, lugares de reunión... La organización de estos espacios, la regularidad de actos observados, pueden ayudar mucho más que una entrevista. Una entrevista es puntual y es el resultado de una interacción irrepetible entre el entrevistador y el entrevistado, suele estar envuelta de una aureola de formalismo que es difícil romper. La información transmitida es enorme y a menudo un poco inabarcable si no se consigue situarla en un marco más amplio. Esto es lo que permite la observación de la cotidianeidad y sobre todo su interacción con ella. La comunidad y lo cotidiano son los límites que delimitan el espacio social donde el etnólogo interactúa: es decir la gente que estudia y la interacción que se crea con ellos. Todas las manifestaciones sociales son buenas a observar (por ejemplo mirar los niños mientras juegan también ayuda a entender el reparto del poder...) a condición de que luego sean sometidas a un análisis antropológico minucioso y que se puedan resituar en un marco de relaciones sociales globales. Esto es lo que se podría llamar el valor heurístico de la rutina del terreno.

\section{Aparición de nuevos líderes y de otros espacios de poder}

Las autoridades tradicionales del pueblo de Saba asientan su legitimidad en dos aspectos, su profundo anclaje histórico y su posición en el parentesco. Su grado de confluencia con estos aspectos les abre la puerta a diferentes funciones. A partir de ahí, si sus acciones responden a lo que se espera de ellos según el cargo que desempeñan, pueden ver ampliada todavía la legitimidad y el prestigio que tienen de por si, lo que les permite convertirse en personas clave. De todos los notables sólo hay unos cinco que se pueden considerar personas clave. Es importante describir este punto porque en Saba nos damos rápidamente cuenta que a parte de las autoridades tradicionales (es decir, el jefe del pueblo, las personas que conforman el consejo de notables, los jefes que gestionan los distintos recursos naturales) existen toda una serie de personas que sin tener la etiqueta de notables son muy, y a veces más, influyentes. Estas personas se transforman rápidamente en personas claves aunque no desarrollen ninguna función.

Como vemos las elites locales no conforman un conjunto homogéneo. Ni todas las funciones tienen la misma autoridad, ni todos los cargos permiten la misma 


\section{perifèria}

Número 4, junio 2006

www.periferia.name

capacidad de maniobra, ni tienen todos la misma influencia. Es por ello que me he propuesto dividir el conjunto de personas influyentes en dos grupos, los notables y los líderes. Para pasar del nivel del pueblo al del municipio (me refiero a la actividad política de cara a las elecciones), movimiento que no dan los notables, hace faltar crear la imagen del líder, actor que lucha en varios niveles distintos para obtener legitimidad y poder. La diferencia fundamental entre estos dos grupos es su nivel de coherencia con la tradición. Los primeros, los notables, son personas a las que se ha atribuido un cargo o una autoridad que la mayoría de las veces les viene dada por su edad, su estatus, su filiación, como, por ejemplo, los jefes de linaje. Los segundos, los líderes, son personas que apoyándose en este aspecto aglomeran a su alrededor un conjunto de personas, basándose en una red ya establecida (de intereses, de parentesco, de clientela, de afinidad), o bien utilizando su influencia para crearla (fama, legitimidad, dinero, clientela, relaciones). Ambos, líderes y notables, son personas clave para entender el reparto del poder en el seno del pueblo pero, mientras que los notables tienden a ver su función como un conjunto cerrado de posibilidades y de responsabilidades (aquellas que marca la tradición), los líderes siempre están en movimiento para tener más peso. Mientras que la autoridad de los primeros se fundamenta en una legitimidad difícilmente cuestionable, la autoridad de los segundos radica más en su influencia, su trabajo y en los resultados; su posición parece por lo tanto más sujeta a controversia. La tradición, caracterizada por la reproducción del sistema, es la base de los notables; el movimiento, la de los líderes. Ahora bien, la referencia de la comunidad son los notables, que representan lo inamovible, la seguridad que procuran la tradición y la pervivencia de su sistema. Los líderes son personas que tienen como finalidad el acaparar algo (un recurso económico o sencillamente más poder) principalmente en beneficio propio o de su grupo de interés.

Esta clasificación tiene su dificultad en el hecho de que ambas "personalidades" se confunden constantemente: un notable también puede tener una faceta de líder, y un líder que no proviene de una familia de notables, no podrá alcanzar la influencia del que sí proviene de una familia de notables. Varios ejemplos permiten entender mejor este punto. Nogutu, actual jefe del pueblo, fue uno de los notables que optaban a ser jefe del pueblo cuando el número de personas que tenían derecho a presentarse o ser presentados a jefe era muy limitado (tres o cuatro en todo el 


\section{perifèria}

Número 4, junio 2006

www.periferia.name

pueblo). Una vez elegido jefe del pueblo, en 1978, sus funciones ya estaban claramente delimitadas por la tradición y la costumbre. Su autoridad, que surge de la función que desempeña, es muy grande, pero se enmarca dentro de unos límites preestablecidos y conocidos por todos. No se le pide ninguna innovación sino que haga respetar y sea el garante del orden social imperante. Ahora bien, él puede, gracias a su influencia (sumada a su autoridad), ampliar sus prerrogativas, en cuyo caso empezaría a ser, lo que he considerado como un líder. Al igual que un promotor, el líder traspasa todos los niveles marcados por la tradición para intentar fomentar una actividad (un proyecto de desarrollo...) o una tendencia (política, religiosa, de pensamiento...). Asimismo, mientras que un notable es, en principio, escuchado por todos los que él representa y que comparte con ellos sus decisiones, el líder depende más de las adhesiones que cristalizan alrededor de sus proyectos, sus ideas, sus partidos. Estas adhesiones no son mecánicas (a diferencia del notable) sino que son fruto de su trabajo de persuasión o de influencia².

\section{Notables vs. líderes}

Aunque se podría suponer que aquellos notables que están al frente de los diversos cargos, y que gozan de gran autoridad e influencia, se vuelven casi por inercia líderes locales, vemos que no es el caso en Saba. Los notables de Saba (me refiero al jefe, a los miembros de su consejo y a los ancianos-notables, a los poseedores de los recursos naturales, al imán) mantienen sus prerrogativas y no intentan ampliarlas, por lo tanto no son además líderes. Pero sí es cierto que todas aquellas personas que me han parecido ser líderes son todos, en su mayoría, sobrinos o hermanos menores de notables. En otros pueblos, y eso suele ser una situación normal, el jefe es el notable más importante del pueblo, porque es el que más dinero tiene, lo cual le otorga una red de allegados muy grande y lo convierte en la mayor fuente de capital. Su legitimidad consuetudinaria unida a su poder económico y a sus relaciones suelen hacer de él la persona clave por excelencia, y por lo tanto un líder en todos los sentidos. Hoy día, con la llegada de la política, muchas jefaturas han sabido ganarse un punto más de autoridad y de influencia colocando a algunos de sus miembros como líderes políticos locales. La jefatura del

\footnotetext{
${ }^{2} \mathrm{Si}$ el surgimiento de los líderes y su influencia creciente están en correlación con los cambios sociales y la evolución de los valores que se dan hoy en día entonces también es posible que varias de las tensiones que he notado en el pueblo tengan su punto de partida en esta dicotomía.
} 


\section{perifèria}

Número 4, junio 2006

www.periferia.name

pueblo que está al frente del municipio es un muy buen ejemplo de estrategia familiar de ampliación del poder o de cómo han extendido sus ramas en el mayor número de ámbitos posibles, convirtiéndose en una de las familias más influyentes de la región. En el caso de Saba, Nogutu no tiene el peso que cabe esperar de un jefe, porque es un jefe sin mucha autoridad. Nunca fue una persona adinerada ni antes ni después de su elección. El estatus del jefe es siempre primordial para entender la composición del reparto del poder. En Saba su posición es controvertida, es un jefe que no cuenta con el apoyo de todos. El poder de los notables es mayor que el del jefe: éste no cuenta con la autoridad suficiente en la base. Como en otros muchos pueblos, si se tiene que recurrir a una elección a la hora de designar un jefe, los notables buscan apoyos para sus pretendientes y les ofrecen sus propias redes y evidentemente escogen los pretendientes en función de sus intereses. En todos los casos, el hecho de pasar por una elección indica de por sí que el jefe no será independiente, que para gobernar deberá recurrir mucho al compromiso, y que además los notables tendrán mucho peso en la toma de decisiones. En el panorama político de Saba, se observan dos tendencias: una, que apoyó al jefe actual cuando se presentó (en 1978) y que es todavía muy influyente, y otra que conformaría una especie de "oposición parlamentaria descontenta". Esta división se reproduce en todos los ámbitos sociales.

No obstante, el poder económico no está en manos de los que tienen los cargos consuetudinarios, sino en las de los líderes. Sin embargo, estas nuevas elites provienen de los mismos linajes que los notables más influyentes del pueblo. Son parientes $y$, más específicamente, provienen de contados grupos domésticos ${ }^{3}$ ( 0 segmentos de linajes o familias extensas) pertenecientes a los linajes de mayor estatus. En consecuencia:

- entre notables y líderes hay relaciones de parentesco muy evidentes, y muchas son de primer grado;

- el reparto del poder tiene su punto de partida en distinciones de parentesco, y este en la historia;

\footnotetext{
${ }^{3}$ Los he definido así de forma provisional. En la tesina hay un esquema del parentesco que permite entender mejor este punto.
} 


\section{perifèria}

Número 4, junio 2006

www.periferia.name

- las fricciones en función de las tendencias del pueblo se dan más entre segmentos de linajes distintos que entre linajes o entre clanes;

- los miembros de los linajes de menor estatus parecen estar excluidos de cualquier forma de poder (así como las mujeres y los jóvenes).

\section{Capacidad de liderazgo: condicionamientos}

La continuidad entre el "poder antiguo" y el "poder moderno" es por lo tanto evidente, las nuevas formas de poder (que también se pueden ver como terrenos vírgenes por conquistar, es decir: comités políticos, cargos electos, asociaciones agrícolas, ONG...) están cooptadas por segmentos de linajes o grupos domésticos cuyo patriarca es a su vez un notable importante. Ahora bien, hace falta una solvencia económica que no todos los notables tienen. Ya hemos hablado del jefe, por ejemplo, que ve sus funciones y su legitimidad limitadas por su falta de capacidad de maniobra. En mis observaciones he calculado que tres de entre todos los notables, proceden de grupos domésticos potentes. A su vez también estos mismos grupos domésticos generan líderes. Me refiero a:

1.- Mamadou Traoré (también es consejero del jefe): dos de sus hermanos menores son líderes: uno es primer teniente de alcalde del municipio y presidente de un partido político, el otro es presidente de la asociación de agricultores de Saba.

2.- El imán o Amadou Traoré (considerado también una de las cinco personas más influyentes del pueblo), cuyo sobrino regenta la pinaza ${ }^{4}$ y los camiones que conectan Saba con Mopti, vitales para el comercio, así como presidente de una de las dos asociaciones de jóvenes.

3.- Seinou Kebé (es consejero del jefe y también considerado una de las cinco personas más influyentes del pueblo): Su sobrino o hermano menor es el presidente de un partido político y gran agricultor.

\footnotetext{
4 Barcaza de gran capacidad, característica del curso medio del Níger que permite el transporte de mercancías y pasajeros. Durante los seis meses en que el agua es omnipresente la pinaza de este hombre es casi el único medio de transporte entre Saba y la capital de la región.
} 


\section{perifèria}

Número 4, junio 2006

www.periferia.name

Entre las cinco personas más influyentes del pueblo también se encuentran el decano de la comunidad y el jefe del pueblo, que son junto al imán, las personas de la comunidad que más autoridad y legitimidad tienen. Son la cara visible del pueblo, pero ni el uno ni el otro tienen la capacidad de maniobra suficiente como para reunir esta última condición necesaria que posibilita el paso de notable a líder, que es tener dinero. Hace falta reunir toda una serie de condiciones para ser líder pero la principal, ( $y$ aquí también reside otra gran diferencia entre un líder y un notable) es la capacidad financiera, cuya posesión permite crear o consolidar las demás condiciones necesarias que harán de él una persona clave. Helas aquí:

- Creación o recuperación de redes de dependencia (redes de fidelidad, de obligación). Antiguos cautivos ${ }^{5}$ y personas de condiciones inferiores siempre han sido integrados en el sistema por el fenómeno del clientelismo. Tradicionalmente, alrededor de cada linaje noble gravitan castas inferiores. Éstas se benefician de víveres y ocasionalmente de obsequios. En contrapartida aportan, según sus corporaciones, los instrumentos de trabajo necesarios a sus hospederos, organizan y animan sus ceremonias y manifestaciones y le sirven de intermediario y de empresario. Constituyen buenos aliados para su hospedero en la comunidad (pero entonces cabe preguntarse si las personas inmersas en una dinámica de dependencia entrarán en una lógica de clientes o en una lógica de ciudadanos en el marco de la descentralización).

- Relación de clientelismo, redes de alianzas y de solidaridad

A través de alianzas, basadas en relaciones históricas, matrimoniales, o de intereses, el líder procura ampliar y fidelizar sus redes. Al beneficiario de las liberalidades de uno de estos líderes se le contará como uno de su gente. Éste ya no podrá liberarse como quiera. En mi primer encuentro con el alcalde me dio un billete de 500 francos CFA $^{6}$ diciéndome, "ten, cómprate con esto lo que desees"...

\footnotetext{
${ }^{5}$ La etnia mayoritaria en Saba, los Marka, era antiguamente una sociedad esclavista. Actualmente la división de la población entre nobles y cautivos todavía pervive en el estatus. Asimismo también existen una serie de castas: tejedores, herreros...

${ }^{6}$ No llega a los 90 céntimos de euro, aún así me doy cuenta de que no es una mera anécdota pero no poseo la clave para entender el gesto...
} 


\section{perifèria}

Número 4, junio 2006

www.periferia.name

- Estrategias de ampliación y de apropiación de bienes y recursos. La emergencia de un líder permite ampliar la autoridad de un grupo doméstico - de un grupo de interés a otros recursos u otros medios que le proporcionarán más legitimidad o más dinero y de esta forma harán del líder una persona clave.

- Estrategias de promoción individual. El hecho que sean el núcleo central de diversas redes les permite ser considerados como personas clave en muchos ámbitos. Utilizan su capacidad de mediación y de transmisión para transformarse en referentes ineludibles de su pueblo. Aunque el líder no pueda siempre satisfacer directamente una necesidad (préstamo, parcela agrícola, escribir una carta, resolver un asunto administrativo...), es capaz de ponerte en relación con la persona adecuada. Su posición central en las redes le permite además centralizar toda la información. En Saba los líderes estaban muy poco alfabetizados pero unos pocos hablaban algo de francés y eran capaces de entender el lenguaje burocrático-administrativo que para el resto resulta ininteligible. Asimismo muchos comparten la característica de haber emigrado, a Bamako o a Costa de Marfil. Lo que implica una apertura mayor, en términos de relaciones externas y de acceso a información de fuera del pueblo.

\section{Un nuevo espacio de poder: el binomio complementario, notable-líder}

Al fin y al cabo, sucede como si todas las nuevas fuentes de poder hubieran sido vistas como un terreno virgen susceptible de ser integrado en las posesiones de un grupo de interés. Existe un sólo caso de asociación (presento el listado a continuación) en el que la persona al mando no es familiar de un notable del pueblo: la asociación agrícola de las mujeres. En todos los otros casos, comités locales de los partidos, asociaciones agrícolas, asociación de padres de alumnos, cargos electos..., la persona que dirige la agrupación es miembro de uno de los grupos domésticos más influyentes del pueblo. El repaso de todas estas fuentes de poder permite discernir la influencia de cada una de las elites locales, y su integración en cada estamento. Permite igualmente, en primera instancia, relativizar la influencia de la jefatura tradicional y, en segunda instancia, poner el acento en los líderes actuales del pueblo. 


\section{perifèria}

Número 4, junio 2006

www.periferia.name

- Los poderes electos locales: en todo el municipio, exceptuando a los independientes, existen tres partidos políticos diferentes, US-RDA, ADEMA y $\mathrm{RPM}^{7}$. Cada uno de ellos cuenta con un comité local en cada uno de los pueblos donde está presente y de un comité municipal votado por los comités locales. En las elecciones de 1998, ganó US-RDA después de que todos los demás partidos boicotearan las elecciones. Más tarde el alcalde (miembro de la jefatura de Dialloubé) se cambió de partido y se dio entonces la particularidad de que los que le hicieron alcalde se transformaron en opositores. Durante mi estancia ya se estaban preparando las elecciones que debían celebrarse en abril 2004: US-RDA y ADEMA eran los partidos fuertes puesto que localmente el RPM gira alrededor de una sola persona, muy influyente, pero que vive en un pueblo algo aislado de los demás. Es probable que su actitud se deba más a una estrategia en busca de la autonomía de su familia, la más poderosa de ese poblado, que un intento real de tomar el poder en el municipio.

- Las asociaciones agrícolas: todas ellas están en manos de alguno de los líderes.

- Asociaciones de jóvenes: hay dos, por lo tanto la persona que controla una de las dos asociaciones controla asimismo la mitad de las fuerzas productivas de Saba (en lo referente a los trabajos colectivos).

- La Association Inter-Villageoise (asociación inter-pueblos): el Estado promueve la creación en cada municipio de una asociación que reagrupe a todos los pueblos que lo forman, para así fomentar un punto de encuentro que sirva para proyectar y focalizar las dinámicas del municipio. Aunque la asociación existe, no tiene ninguna influencia en el municipio de Dialloubé; está en punto muerto. Su presidente es el primer teniente de alcalde.

\footnotetext{
7 Estos tres partidos políticos son los principales partidos de Malí. El US-RDA (Unión SoudanaiseRassemblement Démocratique Africain) es el partido más antiguo del país. Creado en 1946 para luchar por la independencia fue el partido del primer presidente del país, Modibo Keita, que luego fue derrocado por el régimen militar de Moussa Traoré. El periodo post dictadura está marcado por el sello del ADEMA (Alliance pour la Democratie au Mali), puesto que desde 1992 hasta 2002 gobernó al país. Aún sin estar al frente del país, el presidente es Amani Toumani Touré que se presentó como independiente, sigue siendo el partido más influyente actualmente (se produjo una escisión durante mi estancia). El RPM (Rassemblement Pour la République) es uno de los muchísimos partidos presentes en Malí (más de 20 tienen escaños en la Asamblea Nacional) de creación más o menos reciente. Se le conoce como el partido del presidente de la Asamblea Nacional.
} 


\section{perifèria}

Número 4, junio 2006

www.periferia.name

- Asociación de padres de alumnos: es el único ejemplo de un movimiento en que el sistema de elección no permite a los líderes controlarlo. La escuela de Saba tiene muy pocos alumnos en comparación con la masa de niños que hay en el pueblo. El sistema educativo normativo y las escuelas en general están todavía muy mal vistas por la población, razón probable por la que esta asociación, que reúne unas veinte personas todas padres de un/a alumno/a, escapa a la avidez de los líderes.

- Los funcionarios: los funcionarios, basándose en sus conocimientos y en su facilidad de entendimiento del entramado burocrático suelen ser líderes naturales en Malí. Son muchos los maestros, médicos y enfermeros del mundo rural que se presentan a alcalde y que son elegidos. Asimismo muchos de ellos son los precursores de iniciativas locales y de proyectos de desarrollo, a través de sus cargos electos o de las asociaciones y de las ONG que ellos ayudan a crear. En Saba no es así porque el maestro no muestra interés por estos asuntos. En la cabeza del municipio también pasa lo mismo, y eso que reúne más funcionarios. Sólo uno, el director del colegio de ese pueblo, fue candidato en las pasadas elecciones y también tenía la intención de presentarse a las elecciones municipales de abril 2004. Pero él también es miembro de la jefatura de ese pueblo... Pienso que su comportamiento es más fruto de su estatus social (al ser maestro tiene la etiqueta de intelectual) y de sus propios intereses en el pueblo que un modelo del comportamiento de los maestros, cuya tendencia generalizada es la de interesarse por los asuntos políticos locales y de ser vectores de las políticas gubernamentales.

El siguiente cuadro nos permite visualizar hasta qué punto las mismas personas extienden sus competencias al mayor número de ámbitos de poder. También nos ayuda a discernir la capacidad de maniobra de los líderes, que suele abarcar varios ámbitos muy variados. He escogido estos cuatro grupos domésticos (segmentos de linaje) por ser los más influyentes del pueblo. El estatus adscrito se refiere siempre a la posición social del notable y los distintos ámbitos son los que ocupa el líder que hay en su mismo grupo doméstico. He escogido los distintos ámbitos por ser los más importantes, no solamente en el pueblo sino también en el municipio (es la razón por la que incluyo el comercio). 


\section{perifèria}

Número 4, junio 2006

www.periferia.name

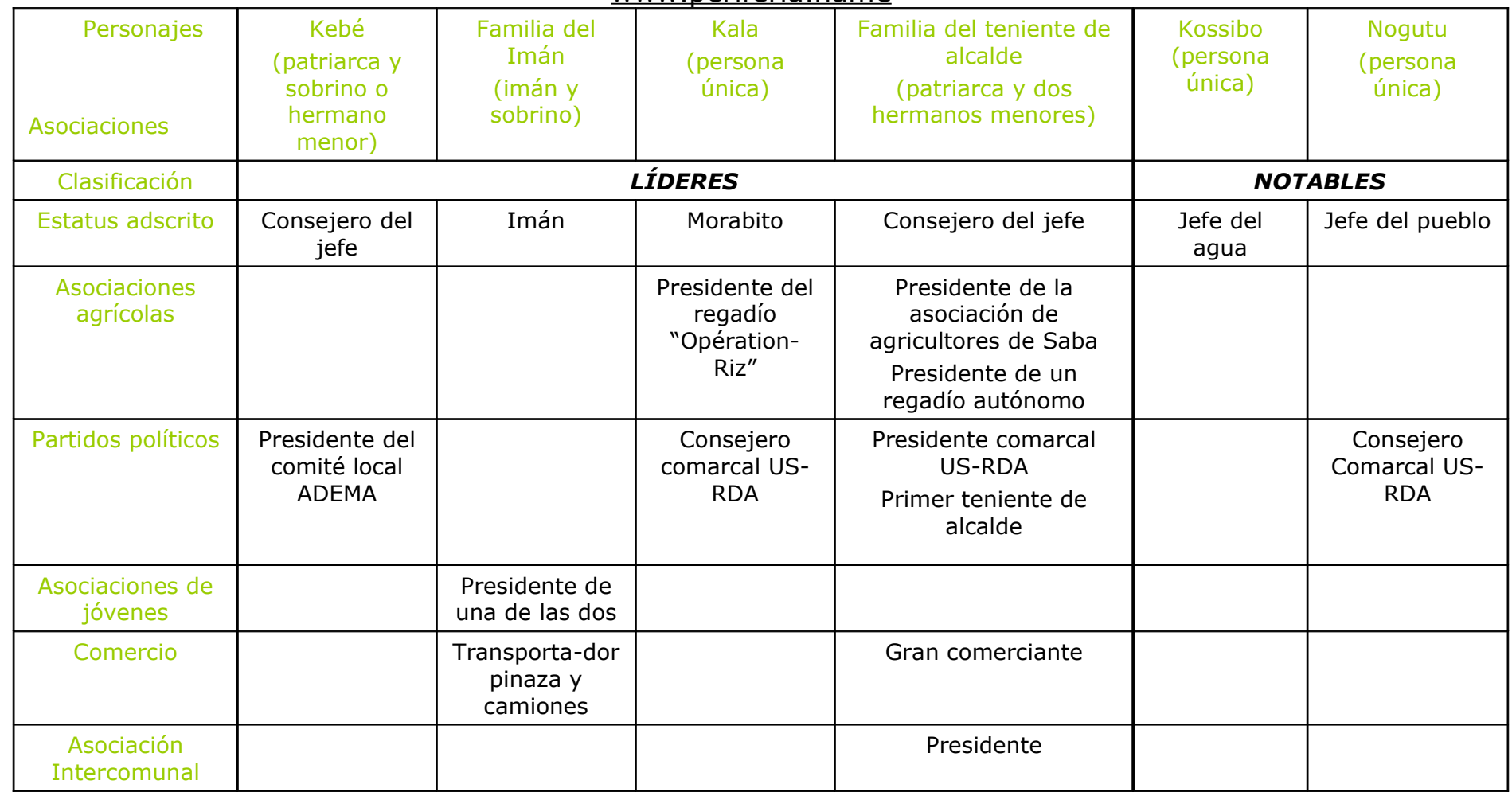

Cuadro 1. Área de influencia de los líderes según su grupo de pertenencia y comparación con las dos familias "poseedoras", según la tradición, de la autoridad en Saba y del control de los recursos naturales.

Este cuadro nos confirma que es un error imaginar que el líder es una entidad autónoma. Considerarlo como representante de un todo, de una relación entre líder y notable es más ajustado a la realidad. Este binomio es lo que da fuerza al líder puesto que le enraíza a nivel local y le da acceso a las redes de su grupo de origen. Vemos igualmente que los mejores ejemplos de poder consuetudinario (autoridad en el pueblo y sobre los recursos naturales), como son el jefe del pueblo y el jefe del agua, no tienen la influencia suficiente como para extenderse y ampliar su área de poder al nivel del municipio ${ }^{8}$. Estas nuevas elites locales tienen mucho parecido con los Big Men. La lógica del Big Man -según Jean-François Médard que adapta este concepto clásico a la realidad africana- estriba en el:

modo de acumulación de recursos de naturaleza variada basado en el intercambio simbólico y social: el "big man" acumula riqueza a fin de distribuirla; distribuyéndola, la consume, pero la transmuta en capital simbólico del cual una parte es convertida a su vez en riqueza. [...].

\footnotetext{
${ }^{8}$ Es cierto que el jefe es consejero comarcal pero han sido otros líderes que lo han integrado en la
} política, no es por capacidad propia. 


\section{perifèria}

Número 4, junio 2006

www.periferia.name

Basándose en estos recursos económicos que ha acumulado de esta manera, invierte parte de su riqueza en maniobras económicas diversificadas; al mismo tiempo convierte la otra parte de su riqueza en capital simbólico, bajo la forma de apoyos políticos, redistribuyéndola. [...]. El capital político permite a su vez extraer más recursos económicos. Lo importante aquí no es tanto la naturaleza de los recursos controlados al principio sino el proceso de interacción entre esos recursos. La "intercambiabilidad" entre los recursos tiene como consecuencia que buscar el poder político y buscar la riqueza es lo mismo, porque si hay que tener poder político para ser rico, hay que ser rico para conservarlo (1992: 172).

Volviendo a nuestro contexto y salvando diferencias -ya que Médard aplica este concepto a personalidades importantes del mundo de la política y de los negocios ${ }^{9}$ esta lógica del Big Man explica la imbricación de las posiciones que se detecta a través del cuadro. Cada líder busca ampliar su influencia al mayor número posible de estamentos. También nos permite entender la necesidad que tienen, ya que en Saba no tienen acceso directo a posiciones políticas, de apoyarse en algún notable que les facilite una legitimación que la economía como tal no les puede aportar.

Estos líderes son por lo tanto los intermediarios entre el pueblo y el exterior, las piezas a través de las cuales se introducen cambios en la zona. De ahí la importancia que cobran (más que los notables) en la aplicación de la descentralización y de las acciones de desarrollo ${ }^{10}$.

Es importante resaltar igualmente otra característica que marca la diferencia entre las nuevas elites locales y los notables. No luchan por los mismos objetivos ni tienen las mismas aspiraciones: el ideal comunitario no es para ellos lo más importante. El interés personal así como el de su grupo tiene preferencia. Asimismo deslealtades y otras estrategias, aunque mal vistas según criterios tradicionales, son consideradas armas válidas en las contiendas entre líderes.

\footnotetext{
${ }^{9}$ Ver su artículo Charles Njonjo: Portrait d'un "Big Man" au Kenya (1987) en el que sigue toda la carrera de un político importante e influyente de Kenya.

${ }^{10}$ Bierschenk, Chauveau y Olivier de Sardan Ilaman a estos personajes "corredores (o promotores) del desarrollo" y los definen de esta manera: "Los corredores del desarrollo son actores sociales implantados en una arena local (en la que juegan un papel político más o menos directo) y que sirven de intermediarios para atraer (hacia el espacio social correspondiente a esta arena) recursos exteriores que provienen de la ayuda al desarrollo. Si tomamos el "proyecto de desarrollo" como la forma casi ideal-típica de la operación de desarrollo, sea cual sea el operador, los corredores representan los portadores sociales locales de proyectos; aseguran un intercambio entre los destinatarios del proyecto y las instituciones de desarrollo; son considerados representantes de la población" (2000: 7). Basta cambiar la palabra proyecto por descentralización y esta noción cobra sentido en la realidad de los líderes de Saba.
} 


\section{perifèria}

Número 4, junio 2006

www.periferia.name

Ésta es la razón por la que cabe además integrar la noción de control como otra diferencia entre líderes y notables. Como representante de la comunidad, el notable se enfrenta a un control, mayor o menor según sus funciones, por parte de los que se sienten representados por él porque le eligieron (un grupo doméstico en el caso de un patriarca, de un linaje en el caso de un jefe de linaje, o el pueblo entero en el caso del jefe del pueblo o de sus consejeros). Asimismo el notable soporta su propio autocontrol: respetar y cumplir las reglas y la costumbre, seguir las prerrogativas de su cargo... Mientras que en las áreas de poder, vírgenes, donde maniobran los líderes, todavía no hay reglas a las que atenerse. No existe un modus operandi normativo, ni hay "tradición" ni "costumbre" que regule el cómo de su acción ni se han instaurado todavía normas específicas. Hay casos en que la noción de control existe como estrategia propagandística: es el caso de algunos candidatos que claman que su gestión será transparente, o que gestionarán todos los asuntos de forma consensuada. Pero es más un eslogan que una realidad. A menos que sus acciones sean nocivas, o que mientan o engañen, tienen mucho margen de maniobra.

La descentralización reclama un alto nivel de democratización, así como que exista la conciencia de "bien común" compartido entre personas que no son de la misma aldea o del mismo parentesco. El gobierno del Malí es consciente de que no es éste el caso, y la descentralización no es vista como una transferencia de poder a zonas que son democráticas según estándares occidentales y por lo tanto aptas a manejar esta descentralización; al contrario, la descentralización es vista como una herramienta para democratizar la población y las zonas rurales en un futuro próximo (siempre según estándares occidentales que por cierto niegan que exista algún tipo de democracia en el África tradicional). Los líderes son conscientes de ello y saben que el propio gobierno les deja un gran margen de maniobra, lo cual a su vez les confiere un cierto grado de inmunidad. Es lo que el Gobierno justifica con un eufemismo más o menos parecido a este: "los inevitables errores en la introducción de una nueva reforma" ${ }^{\prime 11}$. No estoy aquí haciendo una crítica de la

\footnotetext{
11 Los propios agentes del Ministerio de la Descentralización con los que me crucé en Saba cuando vinieron para inspeccionar las arcas del municipio y la gestión del alcalde, que había sido denunciado por malversación de fondos, me confirmaron esta impresión. Me dijeron que el alcalde había cometido el delito de falsificación y de uso de documentos falsificados (más tarde pasaría una noche en el calabozo y pagaría una elevada fianza por no haber correspondido a una citación judicial). También añadieron que no le harían nada, que no había malversado mucho dinero, que era probablemente más bien fruto de un error, y que venían para se que controlara la situación por sí sola y que se viera contundentemento amo
} 


\section{perifèria}

Número 4, junio 2006

www.periferia.name

actitud del Gobierno ni pretendo dar una imagen negativa de la gestión municipal; cuando me refiero al ancho margen de maniobra que tienen los líderes no quiero que se malinterprete entendiendo que pueden malversar fondos o hacer lo que quieran con total impunidad; sino que llevan a cabo acciones que consideran buenas para el municipio o para una parte de él, pero que suelen también beneficiar particularmente a su grupo de interés. Es el caso del proyecto de un canal, financiado en parte por el ayuntamiento, que beneficia sobre todo a una aldea; o prevalecer la financiación de campañas de vacunación del ganado, con prioridad para los Peul, etnia de ganaderos. Por otro lado cuando el beneficio es únicamente personal, por ejemplo malversando fondos, todo el mundo lo criticará y lo denunciará, si puede.

Para que la reforma funcione, debe pasar mucho tiempo, y hacer de ella un elemento de presión hacia las elites locales puede ser peligroso para el Gobierno. Cuando volví a Bamako, en diciembre de 2003, aprendí que ningún alcalde en todo el país había sido arrestado, o cesado en sus funciones, y ello a pesar de que el Ministerio había recibido muchas denuncias. Esta situación refuerza el sentimiento de impunidad entre los líderes. Y efectivamente si únicamente la tradición y la costumbre son reguladoras (y lógicamente, la tradición no ha tenido nunca la necesidad de crear un modo operativo o una ética para un puesto de alcalde por ejemplo...), los líderes todavía tienen algunos años por delante para sentirse con las manos libres. Esta situación sólo acabará cuando las nuevas áreas de poder surgidas con la descentralización- ya no se parecerán a una especie de jungla en la que todo está permitido:

- $\quad$ por el Gobierno, por un lado, hasta que tenga noticia de lo que pasa;

- por la población, por otro lado, hasta que quede informada de sus derechos y hasta que los propios grupos de oposición en el municipio aprendan, admitan y sigan las reglas del juego democrático (al que se les pide que jueguen).

nadie puede hacer lo que quiera, para en cierta forma demostrar que el Gobierno está por encima de la gestión municipal y la controla. 


\section{perifèria}

Número 4, junio 2006

www.periferia.name

El líder se verá controlado por su grupo doméstico y también -en menor medidapor el grupo que le ha permitido llegar a este nivel. A priori el control es relativo puesto que buscan un mismo objetivo y tienen intereses comunes. Él satisface a sus aliados con una serie de medidas que les son favorables, pero siempre seleccionadas estratégicamente para mantenerlos en esa postura de aliados. Parece ser que la gente es mucho más tolerante con el poder adscrito que con el poder adquirido. Todo el mundo se siente afectado por un estatus adscrito ya que es un poder del pueblo para el pueblo. No se le perdonan los errores a los jefes; por ejemplo, se criticará muchísimo al jefe de un pueblo si se piensa que acapara sin redistribuir, o bien sencillamente si se considera que su parte es exagerada. Mientras que se tolera más fácilmente los defectos de aquellas personas que se han ganado su estatus por méritos propios. Si uno de los que he clasificado como líder malversa parte de una subvención, o se queda con una parte de los alimentos o de los materiales aportados por un proyecto, no se le increpará a menos que la situación sea llamativa. Pienso que debido al control social, un notable es controlado en sus acciones, pero también en sus represalias hacia los que le reprochan algo. A lo mejor no se critica mucho a los líderes porque éstos tienen más capacidad de respuesta. Pero también puede ser sencillamente debido a su falta de representatividad. Al no ver estas áreas de poder como un bien común y de todos, la población se desentiende más de lo que pasa en los niveles superiores, como son los asuntos que afectan al municipio o los proyectos de desarrollo.

Esta reforma de descentralización provoca una situación de recolocación de los diversos poderes existentes, en la que los antiguos actores enarbolan sus legitimidades consuetudinarias, mientras que nuevos actores surgen intentando tomar parte en esta nueva gobernabilidad local. En definitiva quién tomará el mando en el municipio no es la pregunta clave por que es evidente que más que las personas que están en el poder lo que está cambiando es más bien el poder en sí ¿Podemos dudar de su capacidad de seguir siendo en el futuro un vector de cohesión social?

\section{Bibliografía}

Bierschenk, Thomas ; Chauveau, Jean-Pierre ; Olivier de Sardan, Jean-Pierre, dirs. (2000). Courtiers en développement. Les villages africains en quête de projets. Paris, Karthala. 


\section{perifèria}

Número 4, junio 2006

www.periferia.name

Médard, Jean-François (1987) "Charles Njonjo: Portrait d'un "Big Man" au Kenya". En: Terray, Emile (dir.) L'État contemporain en Afrique. París, L'Harmattan, p. 4987.

Médard, Jean-François (1992) "Le "Big Man" en Afrique: esquisse d'analyse du politicen entrepreneur". París: L'année Sociologique, n042 "La sociologie du développement: Bilan et perspectives", p. 167-192. 